\title{
A controlled trial of a school-based intervention to improve asthma management
}

\author{
D.C. McCann*, J. McWhirter" ${ }^{\#}$, H. Coleman`, M. Calvert ${ }^{+}$and J.O. Warner ${ }^{\S}$
}

ABSTRACT: The present study investigated schools as an appropriate context for an intervention designed to produce clinical and psychological benefits for children with asthma.

A total of 193 out of 219 (88.1\%) children with asthma (aged 7-9 yrs) from 23 out of 24 (95.8\%) schools completed the study. Intervention schools received a staff asthma-training session, advice on asthma policy, an emergency $\beta_{2}$-agonist inhaler with spacer and whole-class asthma workshops. Nonintervention schools received no asthma-related input.

Intervention children required less general practitioner-prescribed preventer medication despite no differences in symptom control compared with the nonintervention asthmatic group. Increased peer knowledge of asthma may have mediated improved active quality of life in the intervention group, together with increased self-esteem in young females. Those females not receiving the intervention, but identified as being asthmatic within the classroom, and thus possibly stigmatised, reported decreased self-esteem. Lower self-esteem in young males was associated with pet ownership. No change was found in staff knowledge, the establishment of asthma policies or school absences which were low even before intervention.

In conclusion, a whole-school intervention can improve the health of children with asthma when followed with support for all children but effects are likely to be modified by sex and the home environment.

\section{KEYWORDS: Asthma, intervention, pets, psychological, schoolchildren}

E pidemiological studies have indicated that amongst children of school age $\sim 20 \%$ has a diagnosis of asthma [1]. This imposes significant restrictions on physical activities and can affect school attendance [2-4] and performance [5]. Night-time awakenings and poor disease control [6] result in reduced perceptions of self-esteem and increased behaviour problems [7-9]. Despite this, evidence suggests that teacher knowledge and training in asthma management is low, asthma records are incomplete, and effective child self-management of inhaler therapy is unsatisfactory [3, 10-12].

A number of initiatives have been established to overcome this problem [13-15]. Such interventions can increase the knowledge of asthma in teachers [3, 16, 17]. However, it has been more difficult to demonstrate that they have a direct impact on disease outcome measures. Programmes focusing on school-based treatment, asthma management education and peer-led initiatives have had some success [18-20], but limited progress has been made in encouraging schools to set up asthma policies $[13,15,21]$.
Interventions in schools have focused on children with asthma alone and the present authors are not aware of any studies evaluating a wholeschool approach with monitoring of clinical and psychological outcomes. However, it is clear that factors outside the school environment may compromise the efficacy of a school-based approach. The hypothesis of the current authors, on which the study was based, was that a wholeschool intervention would produce clinical and psychological benefits for children with asthma, but factors outside the school, such as home environment, could compromise the impact of the strategy.

\section{METHODS}

\section{Participants}

Recruitment of schools and participants in the south of England is outlined in figure 1. There were no differences in demographic characteristics of school type, area, geographical location, total school roll and percentage of children receiving free school meals between those schools who agreed to participate (25 out of 33 ) and those who refused (eight out of 33).

\section{AFFILIATIONS}

*Schools of Psychology and

+Education, and

${ }^{\S}$ Child Health (Allergy and

Inflammation Sciences), Division of Infection, Inflammation and Repair, University of Southampton, Southampton, and

\#Education and Prevention,

DrugScope, London,

"Portsmouth Primary Care Trust,

Dunsbury Way Clinic, Havant, UK.

CORRESPONDENCE

D.C. McCann

School of Psychology

University of Southampton

Highfield

Southampton

S017 1BJ

UK

Fax: 442380598941

E-mail: dcm1@soton.ac.uk

Received:

March 242004

Accepted after revision:

January 032006

\section{SUPPORT STATEMENT}

This study was funded by a National Health Service Research \&

Development Grant (Project AM1/08/ 008) administered by the National Asthma Campaign. 


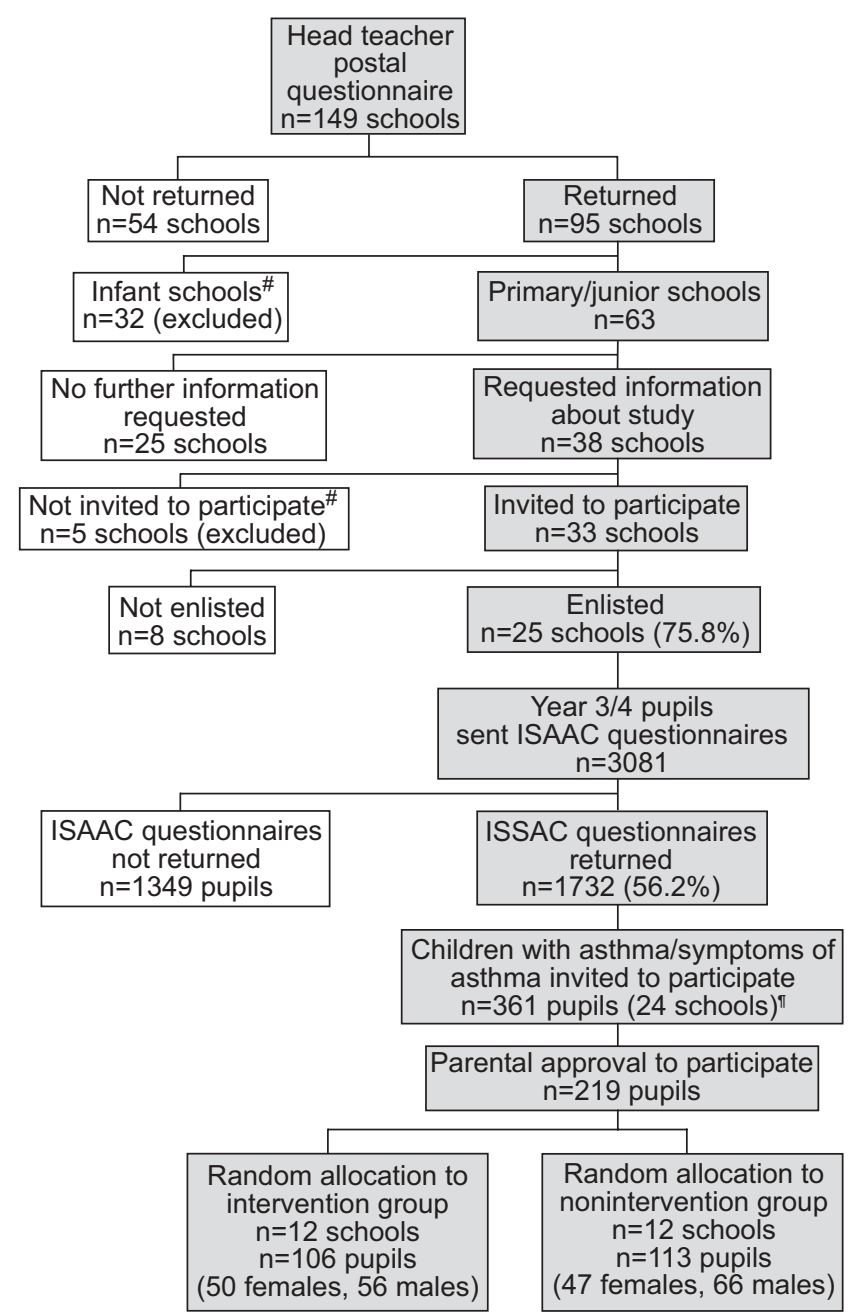

FIGURE 1. Enlistment of participants and schools. ISAAC: International Study of Asthma and Allergies in Childhood; *: Inclusion criteria: only primary/junior schools with school roll of $\geqslant 200$ children; " $^{\circ}$ one school withdrew after ISAAC completion because of a failed Office for Standards in Education inspection.

The parental International Study of Asthma and Allergies in Childhood asthma questionnaire [22] was issued via schools to parents of all the children (aged 7-9 yrs) in Years 3 and 4. On the basis of information relating to a current diagnosis of asthma, the use of asthma medication and symptoms of wheeze over a previous 12-month period, 361 children and their parents in 24 schools were invited to participate in the study; of these, 219 agreed. Pairs of schools were matched on demographic characteristics and randomly assigned in pairs to the nonintervention (NI) group (12 schools; 113 pupils with asthma: 66 male, 47 female) and the intervention (IV) group (12 schools; 106 pupils with asthma: 56 male, 50 female).

\section{Intervention}

Table 1 provides an outline of the nurse-led intervention consisting of a staff training session (duration $\sim 45 \mathrm{~min}$ ) and asthma workshop for pupils (duration $45 \mathrm{~min}$ ). A model asthma policy relating to the care and management of asthma was offered to schools based on examples used in previous studies [17], and the National Asthma Campaign information pack for schools [23], as well as further support and advice when writing their own policies.

The class teacher was present at the nurse-led pupil workshops. In IV schools these workshops focused on asthma as a cause of cough and wheeze, a description of the respiratory system consistent with the Science National Curriculum for pupils aged 7-9 yrs, and what it feels like to have asthma and how to help a friend who is coughing and finding it difficult to breathe. The latter involved a role play with a school nurse as the teacher, where the importance of taking the teacher to a coughing child, rather than the child to the teacher, was emphasised. Pupils with asthma were invited to participate as experts if they wished, but were not compelled to do so. Children in NI schools took part in a workshop about the respiratory system and how the body defends itself against infection, also consistent with the National Curriculum. No mention was made of asthma during this NI workshop.

\section{Outcome measures}

Outcome measures are shown in table 1. The primary aim of the present study was to reduce school absences. Prior to the staff training session and the pupil workshop, staff knowledge of asthma was measured using a questionnaire [24] that was hand delivered to and collected from schools after completion, and pupil knowledge was measured using a Draw and Write technique [25]. Asthma symptom occurrence was recorded [22] and prescribed medication use was assessed using British Thoracic Society treatment step guidelines [26]. Quality of life (QoL) [27] and self-esteem [28, 29] measures were collected from the children with asthma and from a volunteer sample of school peers in Years 3 and 4 . All measures were collected prior to the intervention and in the post-intervention period $1 \mathrm{yr}$ later.

\section{Home and school environment}

Environmental factors with a possible confounding effect on outcomes (table 1) were recorded at baseline only.

Social deprivation indicators [30] were recorded at baseline, as well as the presence of pets at home (dogs, cats, other furry animals, birds, etc). Exposure to environmental tobacco smoke was also measured. A cotinine/creatinine ratio was assessed by cotinine assay of children's urine samples, collected according to the manufacturer's instructions [31] and analysed at Southampton General Hospital, Southampton, UK. Results were expressed as ng of cotinine per $\mathrm{mg}$ of creatinine and a standard cut-off point of $>30 \mathrm{ng} \cdot \mathrm{mg}^{-1}$ of creatinine used to compare cotinine/creatinine levels with parental reports of smoking [32]. Baseline measures of urinary eosinophil protein $X$ were also derived from urine samples using a specific competitive radioimmunoassay in order to provide a more objective marker of allergic inflammatory activity [33], with results expressed as micrograms of urinary eosinophil protein $X$ per mmol of creatinine. House dust mite exposure in the school environment was recorded using house dust mite samples collected over an area of $1 \mathrm{~m}^{2}$ in Year 3 and Year 4 classrooms using various sampling locations [34] so that levels associated with a risk of sensitisation could be assessed [35].

\section{Statistical analysis}

The power of the current study was based on previous reports of time lost from school in wheezing children [36]. Allowing 


\section{TABLE 1 School-based intervention, outcome measures and possible confounding factors}

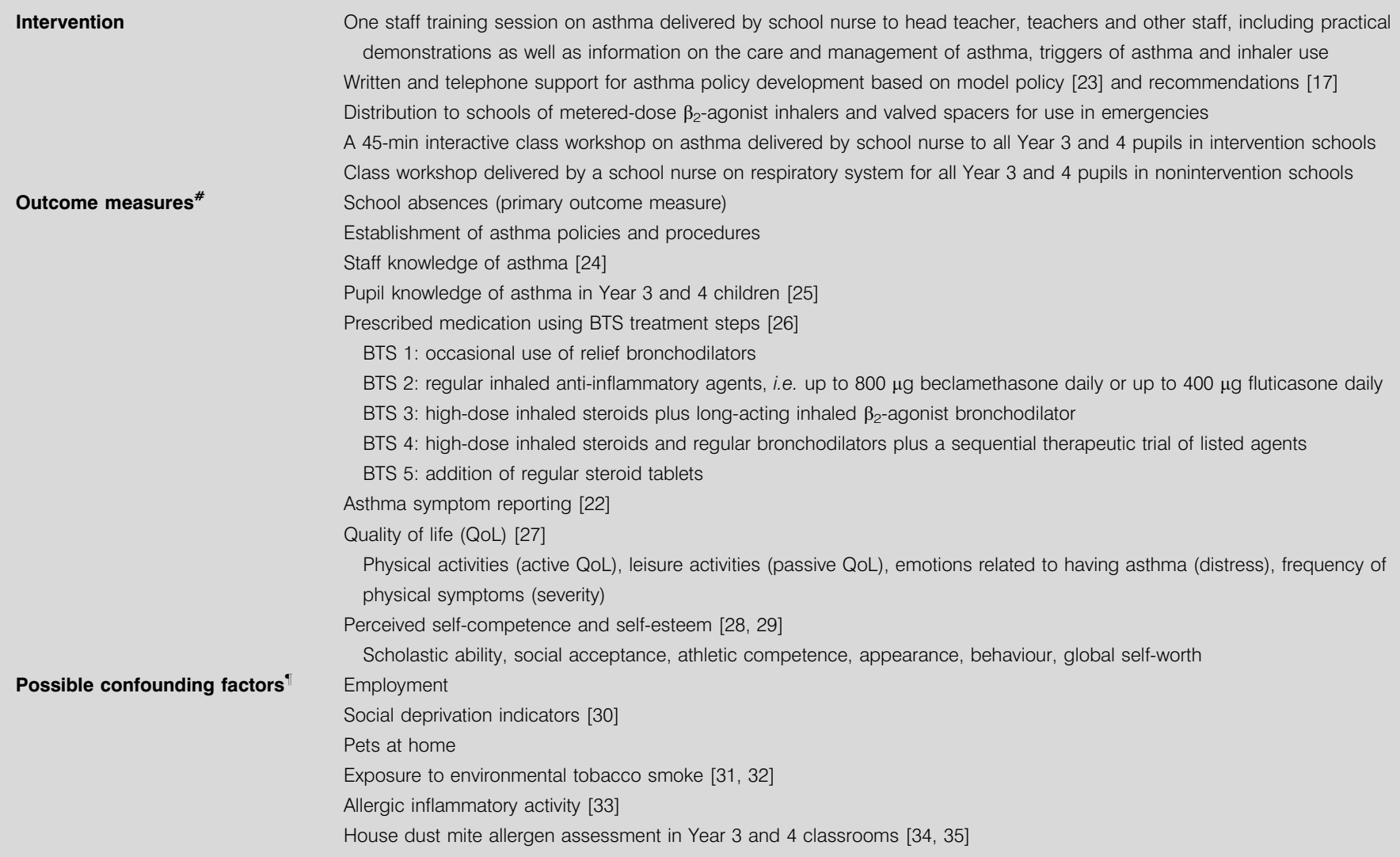

BTS: British Thoracic Society; ${ }^{\#}$ : Collected pre- and post-intervention; " : measured at baseline only.

for clustering (intracluster correlation $=0.05$ ), a sample size of $\sim 100$ pupils (10 pupils per school) in both the IV and NI groups was adequate to provide an $80 \%$ power to detect an effect size of 0.5 (a difference of 5 days) in school absence over the previous school year. Chi-squared, McNemar and Marginal Homogeneity tests were used to examine distribution and changes in responses. Spearman's rho was used to measure correlation and Cohen's kappa to measure agreement. Multivariate ANOVA was used to detect differences between groups in changes in scores (self-esteem, QoL).

\section{RESULTS}

\section{Participants and schools}

A total of 23 out of 24 (95.8\%) schools completed the study (fig. 1). One school withdrew as the result of a change in head teacher. In total, 20 children moved out of the area and a further six children were withdrawn from the study because they or their school withdrew. A total of 193 out of 219 (88.1\%) children with asthma completed the study.

Table 2 shows the distribution of variables measured at baseline due to their possible confounding effect. No significant differences were found in the distribution of these variables over both the IV and NI groups. Moderate agreement was found between parental reports of smoking at home and cotinine/creatinine ratio levels (kappa $=0.38 ; \mathrm{p}<0.0005)$. School environments were found to be relatively house dust mite allergen free with only four schools (two NI, two IV) having a Dermatophagoides pteronyssinus antigen 1 level $>2 \mu \mathrm{g} \cdot \mathrm{g}^{-1}$, the level associated with a risk of sensitisation, but well below $10 \mu \mathrm{g} \cdot \mathrm{g}^{-1}$, at which there is a risk of acute reactions in a sensitised individual [35].

\section{Effect of the intervention}

No differences were found between NI and IV groups in outcome measures prior to the intervention.

\section{Asthma policies and procedures}

One in three schools had written policies at the start of the study $(\mathrm{NI}=$ three policies; $\mathrm{IV}=$ five policies). At the end of the study, six schools in the IV group had written policies and one had "written guidelines". Three of the five IV schools, originally with policies, had amended or updated their policies.

\section{Staff knowledge of asthma}

Questionnaires relating to asthma knowledge were distributed to staff (teachers, lunch-time supervisors, caretakers and secretaries) in schools. While 481 members of staff completed a questionnaire pre-intervention, only 149 (31\%) of these staff members completed post-intervention questionnaires. This prevented any meaningful analysis of the data. Noncompletion was attributed to pressure of work or transfer of staff between schools. At both pre- and post-intervention, there 


\begin{tabular}{|c|c|c|}
\hline & $\begin{array}{c}\text { Nonintervention } \\
\text { group }\end{array}$ & $\begin{array}{l}\text { Intervention } \\
\text { group }\end{array}$ \\
\hline Subjects $n$ & 100 & 93 \\
\hline Sex ${ }^{\#}$ males & 55.0 & 51.6 \\
\hline \multicolumn{3}{|l|}{ Employment } \\
\hline Mother only & 10.0 & 8.6 \\
\hline Father only & 24.0 & 21.5 \\
\hline Both parents & 56.0 & 61.3 \\
\hline Unemployed & 9.0 & 7.5 \\
\hline Missing data & 1.0 & 1.1 \\
\hline \multicolumn{3}{|l|}{ Social deprivation index } \\
\hline$>0$ score (higher deprivation level) & 25.0 & 15.1 \\
\hline \multicolumn{3}{|l|}{ Smoking at home } \\
\hline Mother only & 12.0 & 9.7 \\
\hline Father only & 9.0 & 7.5 \\
\hline Both parents & 9.0 & 4.3 \\
\hline Missing data & & 1.1 \\
\hline \multicolumn{3}{|l|}{$\begin{array}{l}\text { Passive exposure to environmental } \\
\text { tobacco smoke }\end{array}$} \\
\hline \multicolumn{3}{|l|}{ Cotinine/creatinine ratio } \\
\hline$<30 \mathrm{ng} \cdot \mathrm{mg}^{-1}$ & 54.0 & 53.8 \\
\hline$>30 \mathrm{ng} \cdot \mathrm{mg}^{-1}$ & 31.0 & 37.6 \\
\hline Missing data & 15.0 & 8.6 \\
\hline \multicolumn{3}{|l|}{ Reported pets } \\
\hline $\operatorname{Dog}^{+}$ & 11.0 & 17.2 \\
\hline $\mathrm{Cat}^{+}$ & 24.0 & 22.6 \\
\hline Dog and $\mathrm{cat}^{+}$ & 12.0 & 5.4 \\
\hline Other furry pet(s)/bird(s) & 15.0 & 21.5 \\
\hline Missing data & 2.0 & 1.1 \\
\hline \multicolumn{3}{|l|}{ Urinary eosinophil protein $\mathbf{X}^{\#}$} \\
\hline$<100 \mu \mathrm{g} \cdot \mathrm{mmol}^{-1}$ & 38.0 & 36.6 \\
\hline $100-200 \mu \mathrm{g} \cdot \mathrm{mmol}^{-1}$ & 36.0 & 41.9 \\
\hline$>200 \mu \mathrm{g} \cdot \mathrm{mmol}^{-1}$ & 11.0 & 12.9 \\
\hline Missing data & 15.0 & 8.6 \\
\hline
\end{tabular}

Data are presented as \%, unless otherwise stated. ${ }^{*}$ : Children; " : households; : \pm other furry pets, bird, etc.

appeared to be a lack of consistency within schools in answers to questions about record keeping, the location of asthma medication and the use of asthma inhalers in the playground or gymnasium. Open and closed questions also appeared to elicit differing responses. At baseline, $88 \%$ of staff agreed that cough can be a symptom of asthma and that exercise can trigger an asthma attack. However, only $16.8 \%$ included exercise in response to open-ended questions about asthma triggers. Similarly, only $17.7 \%$ of staff included colds and flu as a trigger. In response to closed questions, the majority of staff correctly identified the differences between reliever and preventer medications, with $81.4 \%$ (94\% post-intervention) agreeing that relievers should be taken as required, and $75.8 \%$ (95.5\% post-intervention) agreed preventers should be taken every day. Baseline data showed that $48 \%$ of all teachers were not concerned about having children with asthma in their class, but $40 \%$ reported not being confident about dealing with an asthma attack. This did not change significantly in IV schools after the intervention.

\section{Pupil knowledge of asthma}

All children in Years 3 and $4(n=2,023)$ were asked to provide written responses and illustrations for three asthma-related scenarios printed on a worksheet. These scenarios, the criteria denoting an "appropriate" response and the proportion of appropriate responses are presented in table 3 . No difference was found between the NI and IV groups of Year 3 and 4 children in the proportion of appropriate responses reported at baseline. Significant differences in the distribution of responses were found in the post-intervention period arising from increases in the proportion of appropriate responses over all scenarios $(p<0.0005)$ for the IV group who had received the 45 min asthma workshop 1 yr earlier.

\section{Changes in school attendance}

Absence data were available for 186 out of 193 (96.4\%) study children with asthma. A low level of recorded absence over the previous school year was found at baseline (mean 7.0 days, SD 7.4, range $0-42.5$ ). A total of 124 out of 186 children had reported absences of $\leqslant 1$ week. A similarly low absence level was found at post-intervention for all children (mean 6.8 days, SD 6.1, range 0-34.5). Recorded absences of $>7$ days duration in the school year at post-intervention were related to social deprivation measures, but only for males $(r=0.44 ; p=0.009)$. After adjusting for social deprivation, no effect of the intervention was found. Absences were considerably lower than the present authors had anticipated in relation to the power calculations on which the recruitment numbers were based.

\section{Medication levels}

General practitioner-prescribed medication levels $(n=176$ children) recorded for a 6-month period prior to the intervention (no medication: $47.2 \%$; British Thoracic Society (BTS) step 1: $9.1 \%$; BTS step 2: $38.6 \%$; BTS step 3: $5.1 \%$ ) decreased in the post-intervention period $(\mathrm{p}=0.05)$. However, when IV and NI children were classified into three groups (no medication, BTS step 1 and $\geqslant$ BTS step 2 ), the positive change in treatment level was significant $(p=0.01)$ for the IV group but not for the NI group $(\mathrm{p}=0.83)$ with $23.5 \%(\mathrm{NI}=19.8 \%)$ on no or milder medication and $10.6 \%(\mathrm{NI}=18.7 \%)$ receiving a higher level of medication. Most improvement was from $\geqslant$ BTS step 2 to taking no medication (IV 35.7 versus $25.7 \%$ NI) while, compared with the IV group, twice as many children in the NI group increased medication to $\geqslant$ BTS step 2 (IV 11.6 versus $21.4 \% \mathrm{NI})$.

\section{Asthma symptom reporting}

The prevalence of wheeze "in the last 12 months" was recorded at the start of the study and for a 12-month period after the intervention. The 12-month period prior to the study reported prevalence of wheeze $(n=165$ children) as slightly higher for NI $(90.6 \%)$ compared with IV children $(78.8 \%)$, with the difference approaching significance (Chi-squared 3.6; $\mathrm{p}=0.06$ ). Over the study period, there was a significant resolution of symptoms for all children (Chi-squared 21.8; $p<0.0005$ ), but no effect of the intervention was found. The post-intervention wheeze measure was highly significantly associated with medication use in the same period (Chisquared $19.1 ; \mathrm{p}<0.0005)$ and this was so for a range of wheezerelated symptoms. 
TABLE 3 Baseline and follow-up Draw and Write responses for all children in nonintervention (NI) and intervention (IV) schools

\begin{tabular}{|c|c|c|c|c|c|c|c|c|}
\hline & \multicolumn{4}{|c|}{ Baseline } & \multicolumn{4}{|c|}{ Follow-up } \\
\hline & NI & IV & Chi-squared & p-value & NI & IV & Chi-squared & p-value \\
\hline \multicolumn{9}{|l|}{ Scenario 1} \\
\hline $\begin{array}{l}\text { Invitation 1: Chris has woken in the night coughing } \\
\text { and is finding it difficult to breathe. What can } \\
\text { Chris's Mum or Dad do to help? }\end{array}$ & 11.6 & 13.9 & 2.39 & NS & 15.6 & 22.1 & 14.42 & 0.0005 \\
\hline $\begin{array}{l}\text { Invitation 2: What can Chris do to help him/herself? } \\
\text { Appropriate answer: includes mention of an inhaler } \\
\text { and/or call someone }\end{array}$ & 7.7 & 6.6 & 0.75 & NS & 7.8 & 10.9 & 5.9 & 0.02 \\
\hline \multicolumn{9}{|l|}{ Scenario 2} \\
\hline $\begin{array}{l}\text { Invitation 1: Chris is in the school playground, } \\
\text { running and playing on a cold day. He is } \\
\text { coughing and finding it difficult to breathe. What } \\
\text { can Chris' friends do to help? }\end{array}$ & 54.2 & 51.3 & 1.77 & NS & 59 & 64.4 & 6.4 & 0.01 \\
\hline $\begin{array}{l}\text { Appropriate answer: get or tell a teacher and/or get } \\
\text { an inhaler }\end{array}$ & & & & & & & & \\
\hline $\begin{array}{l}\text { Invitation 2: What can Chris do to help him/herself? } \\
\text { Appropriate answer: includes mention of an inhaler } \\
\text { and/or get an adult }\end{array}$ & 5.1 & 4.7 & 0.10 & NS & 7.6 & 11.6 & 9.53 & 0.002 \\
\hline \multicolumn{9}{|l|}{ Scenario 3} \\
\hline $\begin{array}{l}\text { Invitation 1: Chris is in the classroom and is } \\
\text { coughing and finding it difficult to breathe. What } \\
\text { does Chris say to the teacher? }\end{array}$ & 31.1 & 33.9 & 1.71 & NS & 34.2 & 41.1 & 10.78 & 0.001 \\
\hline $\begin{array}{l}\text { Appropriate answer: includes clear description of } \\
\text { symptoms and/or mention of an inhaler and/or } \\
\text { asthma }\end{array}$ & & & & & & & & \\
\hline
\end{tabular}

Data are presented as \% with appropriate answer.

\section{Quality of life}

Those with asthma reported similar levels of active and passive QoL to nonasthmatic children $(n=609)$ in the same year groups.

Controlling for social deprivation, which was significantly related to physical activity in males $(\mathrm{r}=-0.41 ; \mathrm{p}<0.0005)$, it was found that active QoL in males was negatively correlated with asthma severity $(\mathrm{r}=-0.41 ; \mathrm{p}<0.0005)$ but in females was related to passive QoL $(\mathrm{r}=0.42 ; \mathrm{p}<0.0005)$. Unexpectedly, however, expressed emotional distress related to having asthma was significantly related to lower urinary eosinophil protein $\mathrm{X}$ levels in females $(\mathrm{r}=-0.46 ; \mathrm{p}<0.0005)$. Controlling for these factors, a significant intervention effect was found for QoL $(F[1,141]=5.00 ; p<0.05)$ related to physical activity. In the IV group, $42.9 \%$ of children showed a clinically relevant improvement (an increase of $\geqslant 2$ points) in active QoL, while this figure was only $27.1 \%$ for the NI group (Chi-squared 8.1; $\mathrm{p}=0.02$ ).

No significant differences were found for the peer group in active and passive QoL reports at pre- and post-intervention.

\section{Self-esteem}

No differences in self-esteem scores were found between those with asthma and a sample of their school peers $(n=601)$. However, sex differences in self-esteem scores reported in the literature were also found in the present study. Females perceived themselves as more well behaved than males $(p<0.0005)$, and males more athletically competent than females $(p<0.0005)$. Since relationships between domains in children of school age can also vary by sex and across time [34, $35]$, self-esteem scores were examined separately for males and females.

Figure 2 shows that females in the NI group reported falls in self-esteem over all domains while females in the IV group reported increased perceived self-competence and self-esteem. This effect on self-esteem was significant (Pillai's F[6,80] $=2.75$, $\mathrm{p}<0.05)$ with differences reaching significance particularly for the social $(p=0.01)$, athletic $(p<0.05)$ and behaviour subscales $(p=0.001)$. No such differences were found for the peer group of females in the same schools and, compared with this peer 


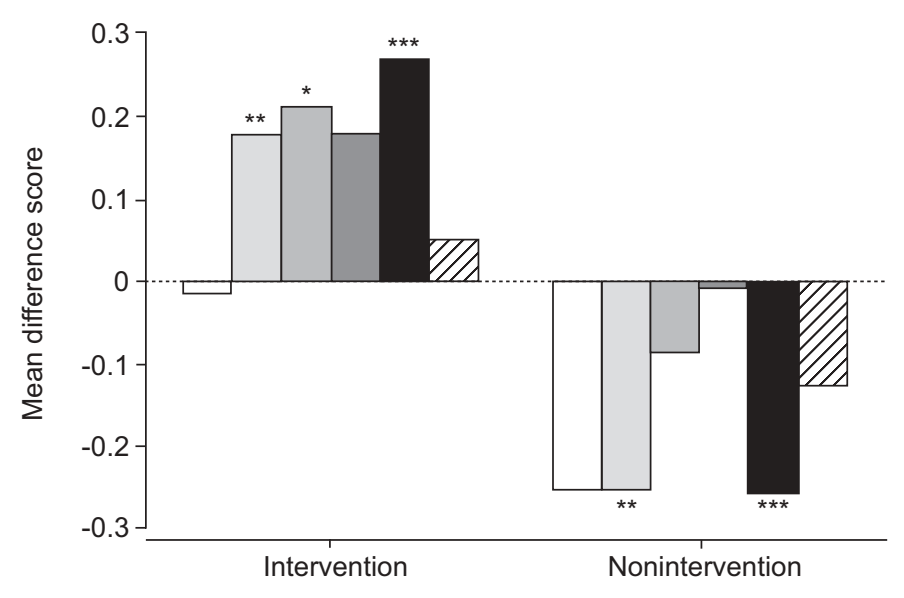

FIGURE 2. Changes in perceived self-competence and self-esteem scores pre- and post-intervention for females in intervention and nonintervention schools. Positive changes indicate an improvement in self-esteem scores and negative changes indicate deterioration in self-esteem scores. $\square$ : Scholastic; $\square$ : social; $\square$ : athletic; $\mathbf{\square}$ : appearance; $\mathbf{\square}$ : behaviour; $\mathbb{Z}$ : global self-worth; *: $\mathrm{p}<0.05$; **: $p=0.01 ; * *: p=0.001$.

group, the improvement in self-esteem for the IV group was significant $(F[6,177]=2.56 ; p=0.02)$ over a number of domains. Similarly, no differences in self-esteem were found for the peer group in NI schools, and compared to this group, the fall in self-esteem for the NI group was significant $(F[6,172]=2.57$; $\mathrm{p}=0.02$ ) over a number of domains. The intervention effect on self-esteem levels, therefore, appeared to be brought about by changes in self-esteem levels for both NI and IV groups of females with asthma.

No similar positive effect of the intervention on self-esteem was found for males with asthma in IV schools (fig. 3) and, similarly, no effect on the peer group of boys. However, pet ownership played a significant role for boys with asthma in changes over the study period. Irrespective of IV or NI group

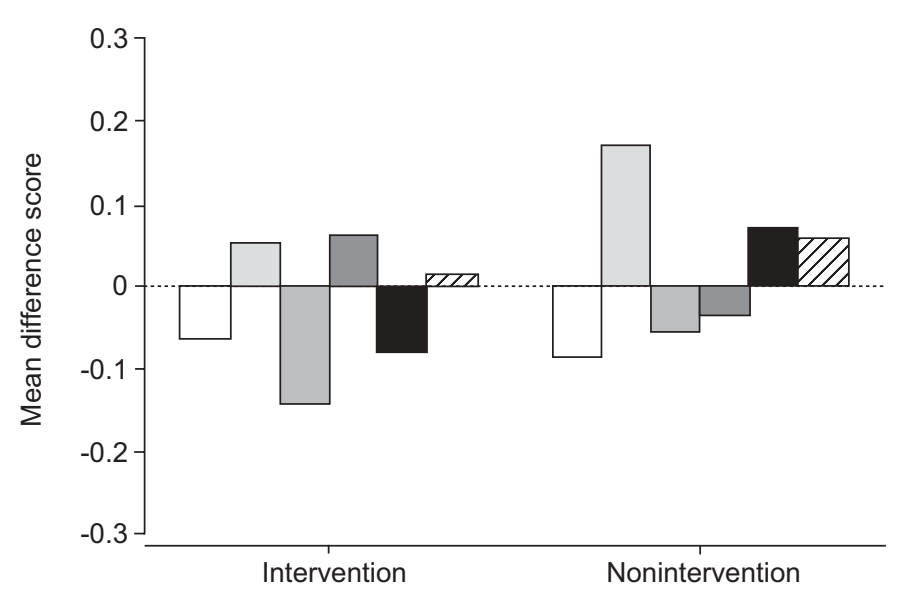

FIGURE 3. Changes in perceived self-competence and self-esteem scores pre- and post-intervention for males in intervention and nonintervention schools. Positive changes indicate an improvement in self-esteem scores and negative changes indicate deterioration in self-esteem scores. $\square$ : Scholastic; $\square$ : social; $\square$ : athletic; $\mathbf{\square}$ : appearance; $\mathbf{\square}$ : behaviour; $\mathbb{Z}:$ global self-worth. membership, boys with pets $(n=62)$ reported decreased selfesteem (Pillai's: $F[6,90]=3.23, p=<0.005$ ) over a number of domains (Social $p=0.002$ ), Athletic $p=0.003$, Appearance $\mathrm{p}=0.003$, Global Self-worth $\mathrm{p}=0.009$ ) compared with those without pets (fig. 4). In this group of boys with pets (dog and/ or cat $n=27$ households; dog and/or cat with other furry animal(s) and/or bird(s) $n=17$; other furry animal(s) only $n=13$; bird(s) only $n=3$; missing reports $n=2$ ), baseline urinary eosinophil protein $X$ levels were positively correlated with parental reports of the impact of wheeze on the child and the child's activities for a 12-month period prior to the urinary measure being recorded $(\mathrm{r}=0.51, \mathrm{p}<0.0005)$ and over a similar period post-intervention, commencing 1 yr later $(\mathrm{r}=0.37$, $\mathrm{p}=0.008$ ). The home environment, therefore, may have moderated the effect of the intervention. Low numbers precluded the investigation of exposure to environmental tobacco smoke.

\section{DISCUSSION}

The current study has shown that the school is an appropriate setting in which asthma management can be improved. Unique to this study is that the intervention included a curriculum-based workshop for all pupils in addition to staff training. The greatest impact was apparently on the peers of asthmatic children. This in turn was associated with significant benefits in terms of the outcome measures for the children with asthma. Not only did this result in improved self-esteem and a clinically relevant improvement in QoL related to physical activity, similar to that found in a previous study [20], but also to a reduced requirement for regular anti-asthma therapy with no resulting deterioration in asthma control. This was significantly different from the NI schools where the asthmatic children did not have the same changes in self-esteem and QoL and continued to require the same amount of prescribed medication.

There were some confounding effects, partly in relation to the sex of the asthmatic child, and also home environment. Reduced self-esteem was found for a group of males with pets for whom urinary eosinophil protein $X$ levels, reflecting

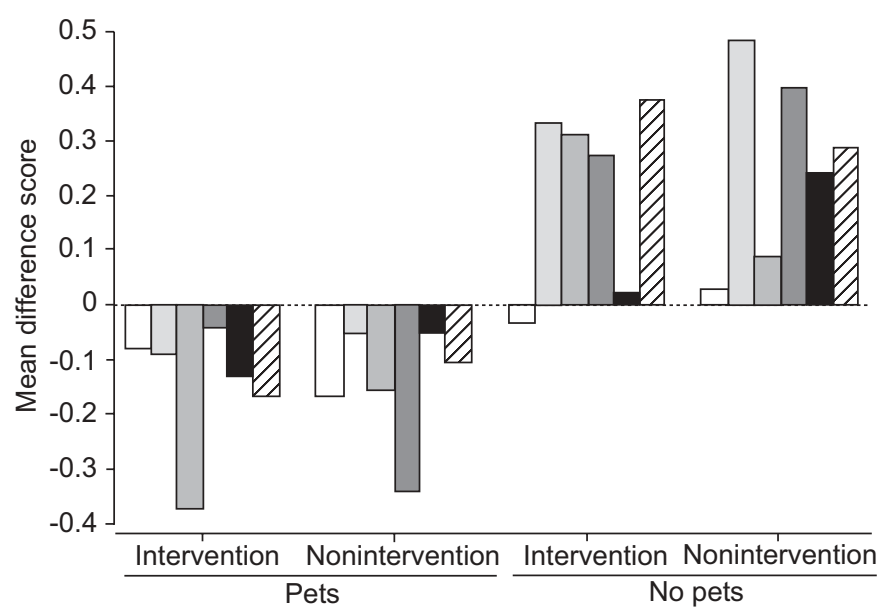

FIGURE 4. Changes in perceived self-competence and self-esteem scores pre- and post-intervention for males by pet ownership. Positive changes indicate an improvement in self-esteem scores and negative changes indicate deterioration in self-esteem scores. $\square$ : Scholastic; $\square$ : social; $\square$ : athletic; $\square$ : appearance; behaviour; $\mathbb{Z}$ : global self-worth. 
allergic inflammatory activity, were significantly related to parental reports of the impact of wheeze on their child and interference in their activities over a fairly long period of time. Low subject numbers prevented investigation of the effect of exposure to environmental tobacco smoke. A recent schoolbased intervention, focusing on asthma treatment, proved effective only for those children who were not exposed to smoke at home [18].

The second extremely important outcome from the present study was that for females in the NI schools whose asthma was identified as a consequence of the research study, there was a decrease in self-esteem. This better identification of children with asthma occurred because all children with asthma in both IV and NI groups completed a daily well-being diary in school over an 18-week period prior to and following the intervention. This diary was retained in school. Diary scores were highly correlated with self-esteem and QoL measures and, therefore, were not included in the analyses. The fall in self-esteem for females in the NI group may well have been as a consequence of stigmatising these females with asthma who were then not supported by any appropriate intervention. This is a very powerful message in relation to future intervention initiatives and to the keeping of asthma registers in school. This should only be considered if the children identified are then appropriately supported with a whole school-based intervention programme.

There is a tendency for investigations of the management of a chronic condition to focus on single interventions. This is the only way it can be established whether components of an intervention package have an evidence base for continued use. However, in reality, interventions are multifactorial. They include a combination of education, social support, environmental manipulation and medication. The present study has shown that while focusing on the school can be worthwhile this does not account for other factors, such as sex and home environments, which will to a certain extent compromise a favourable outcome. The current study did not attempt to optimise the medications but merely to monitor their use as prescribed in primary care during the period before and after the school-based intervention. All the asthmatic children whether they were in the IV or NI schools had some degree of improvement over the year of observation in reported symptoms of wheeze. This is not unexpected in view of the well-known tendency for some degree of improvement during later childhood. No added effect of the intervention on reported symptoms of wheeze was found. However, over and above this, the asthmatic children in the IV schools, while sustaining the same degree of control of their asthma, required less prescribed asthma medication than those in the NI schools. Furthermore, this was associated with improvements in other outcome measures. Therefore, the present authors are very confident that the intervention was efficacious and will be a very worthwhile adjunct to conventional medical approaches. However, it was disappointing that there was only a marginal effect on the asthma policy development and practices in the schools and the authors were unable to solicit sufficient information from the teachers on which to make any judgements as to whether the staff training component of the intervention had any impact. There was a highly significant effect on the asthmatic children's peers, which the current authors suspect was the major factor leading to the improvement in self-esteem in the asthmatic children.

Ostensibly, it is disappointing that the present author's original primary end-point of attempting to reduce absences was not achieved. A number of controlled intervention studies have now failed to find a significant intervention effect on absences in children of this age $[16,20]$, with a further study finding a reduction in both intervention and control groups [19]. This measure may now not be a good marker of asthma morbidity and may be more related to socioeconomic factors. In addition, the schoolchildren with asthma in the present study had relatively mild disease and their school absence record was generally very low and, thus, there was little room for improvement.

\section{ACKNOWLEDGEMENTS}

The authors would like to thank all staff, pupils and parents participating in this study.

\section{REFERENCES}

1 National Asthma Campaign. Asthma Audit 2002: An audit of children's asthma in the UK. The Asthma Journal 2002; 8: Suppl., 1-11.

2 Lenney W, Wells NEJ, O'Neill BA. The burden of paediatric asthma. Eur Respir Rev 1994; 4: 49-62.

3 Fillmore EJ, Jones N, Blankson JM. Achieving treatment goals for schoolchildren with asthma. Arch Dis Child 1997; 77: $420-422$

4 Joint Health Surveys Unit. Health Survey for England (1996). London, Her Majesty's Stationery Office, 1998.

5 Diette GB, Markson L, Skinner EA, Nguyen TTH, AlgattBergstrom P, Wu AW. Nocturnal asthma in children affects school attendance, school performance and parents' work attendance. Arch Pediatr Adolesc Med 2000; 154 923-928.

6 McKenzie SA. Difficult asthma in children. Eur Respir Rev 2000; 10: 18-22.

7 Bender BG. Are asthmatic children educationally handicapped? School Psychology Quarterly 1995; 10: 274-291.

8 Celano MP, Geller RJ. Learning, school performance, and children with asthma: how much at risk? J Learn Disabil 1993; 26: 23-32.

9 Lavigne JV, Faier-Routman J. Psychological adjustment to pediatric physical disorders: a meta-analytic review. J Pediatr Psychol 1992; 17: 133-157.

10 Hussey J, Cahill A, Henry D, King AM, Gormley J. National school teachers' knowledge of asthma and its management. Ir J Med Sci 1999; 168: 174-179.

11 Carruthers P, Ebbutt AF, Barnes G. Teachers' knowledge of asthma and asthma management in primary schools. Health Educ J 1995; 54: 28-36.

12 Brown DC, Patterson W, Edmunds AT. Problems encountered by asthmatic schoolchildren in Edinburgh: acute episodes and medication. Health Bulletin 1998; 56: 858-862.

13 Scotton C, Samuels M. Training and treatment for asthma in schools. The Asthma Journal 2000; 5: 28-31.

14 Hill J. Asthma in schools. Empowering children. The Asthma Journal 2000; 6: 29-31. 
15 Cuffwright ME, Doyle T, Malone M. Working together to manage children with asthma in school. The Asthma Journal 2000; 6: 25-28.

16 Hill R, Williams J, Britton J, Tattersfield A. Can morbidity associated with untreated asthma in primary school children be reduced? A controlled intervention study. BMJ 1991; 303: 1169-1174.

17 Coleman H, Finlay FO, Gregson RK, Warner JO. Asthma management in Southampton schools. Education and Health 1995; 13: 12-14.

18 Halterman JS, Szilagyi PG, Yoos HL, et al. Benefits of a school-based asthma treatment program in the absence of secondhand smoke exposure: results of a randomized clinical trial. Arch Pediatr Adolesc Med 2004; 158: 460-467.

19 McGhan SL, Wong E, Jhangri GS, et al. Evaluation of an education program for elementary school children with asthma. J Asthma 2003; 40: 523-533.

20 Shah S, Peat JK, Mazurski EJ, et al. Effect of peer led programme for asthma education in adolescents: cluster randomised controlled trial. BMJ 2001; 322: 583-585.

21 Danger zone? A National Asthma Campaign report on how schools can be made safer for children with asthma. London, National Asthma Campaign, 1999.

22 Asher MI, Keil U, Anderson HR, et al. International study of asthma and allergies in childhood (ISAAC): rationale and methods. Eur Respir J 1995; 8: 483-491.

23 National Asthma Campaign. Schools' Information Pack. London, National Asthma Campaign, 1999.

24 Brookes J, Jones K. Schoolteachers' perceptions and knowledge of asthma in primary schoolchildren. $\mathrm{Br} J$ Gen Pract 1992; 42: 504-507.

25 Wetton NM, McWhirter JM. Images and Curriculum Development in Health Education. In: Prosser J, ed. Image-based Research: A source book for qualitative researchers. London, Falmer Press, 1998; pp. 263-283.
26 British Thoracic Society. The British guidelines on asthma management 1995 review and position statement. Thorax 1997; 52: Suppl., 51-521.

27 French DJ, Christie MJ, West A. Quality of life in childhood asthma: development of the Childhood Asthma Questionnaires. In: Christie MJ, French DJ, eds. The Assessment of Quality of Life in Childhood Asthma. Chur, Switzerland, Harwood Academic Publishers, 1994; 157-180.

28 Harter S. Manual for the Self-Perception Profile for Children. Denver, University of Denver, 1985.

29 Hoare P, Elton R, Greer A, Kerley S. The modification and standardisation of the Harter Self-Esteem Questionnaire with Scottish school children. Eur Child Adolesc Psychiatry 1993; 2: 19-33.

30 Department of the Environment. Index of Local Conditions: an analysis based on 1991 Census Data. London, Her Majesty's Stationary Office, 1995.

31 Double Antibody Nicotine Metabolite In-vitro Diagnostic Test Kit. Gwynedd, UK, Diagnostics Products Corporation-UK, 2001.

32 Henderson FW, Reid HF, Morris R, et al. Home air nicotine levels and urinary cotinine excretion in preschool children. Am Rev Respir Dis 1989; 142: 197-201.

33 Pharmacia EPX RIA. Uppsala, Sweden, Pharmacia \& Upjohn Diagnostics AB, 1999.

34 Popplewell EJ, Innes VA, Lloyd-Hughes S, et al. The effect of high-efficiency and standard vacuum cleaners on mite, cat and dog allergen levels and clinical progress. Pediatr Allergy Immunol 2000; 11: 142-148.

35 Call RS, Smith TF, Morris E, Chapman MD, PlattsMills TAE. Risk factors for asthma in inner city children. J Pediatr 1992; 121: 862-866.

36 Hill R, Williams J, Britton J, Tattersfield A. Can morbidity associated with untreated asthma in primary school children be reduced? A controlled intervention study. BMJ 1991; 303: 1169-1174. 